\title{
Laryngo-esophageal Dysfunction-free Survival in a Preservation Protocol for T3 Laryngeal Squamous-cell Carcinoma
}

\author{
PHILIPPE GORPHE ${ }^{1}$, MARGARIDA MATIAS $^{2}$, CAROLINE EVEN ${ }^{1}$, CHARLES FERTE $^{2}$, \\ FRANÇOIS BIDAULT ${ }^{3}$, GABRIEL GARCIA ${ }^{3}$, STÉPHANE TEMAM ${ }^{1}$, \\ FRANCE NGUYEN ${ }^{4}$, PIERRE BLANCHARD ${ }^{4}$, YUNGAN TAO $^{4}$ and FRANÇOIS JANOT ${ }^{1}$ \\ Departments of ${ }^{1}$ Head and Neck Oncology, ${ }^{2}$ Medical Oncology, ${ }^{3}$ Radiology, and ${ }^{4}$ Radiotherapy, \\ Gustave Roussy Institute, Villejuif, France
}

\begin{abstract}
Background: We reviewed the outcomes of patients with T3 laryngeal neoplasms with a fixed hemilarynx, a large gross tumor volume or a subglottic extension (SGE), treated with a laryngeal-preservation protocol with induction chemotherapy. Patients and Methods: The study end-points were laryngo-esophageal dysfunctionfree survival (LEDFS), laryngectomy-free survival (LFS), overall survival (OS), and disease-free survival (DFS). Results: A total of 104 patients were included. The 2-year and 5 -year OS rates were $70.4 \%$ and $54.5 \%$, respectively. OS and DFS were independent of the treatment modality in the whole cohort ( $p=0.6546$ and $p=0.3006$, respectively) and in patients with SGE ( $p=0.529$ and $p=0.255$, respectively). The 2-year and 5-year LEDFS rates were $44.3 \%$ and $28.2 \%$, respectively. LEDFS was not associated with initial hemilaryngeal fixation or SGE ( $p=0.5772$ and $p=0.0623$, respectively). Conclusion: Chemoselection is feasible without compromised oncological or functional outcomes in patients with an initially fixed hemilarynx or subglottic extension.
\end{abstract}

In 1991, the Veterans Department phase III trial demonstrated the feasibility of laryngeal preservation in patients with advanced-stage laryngeal squamous-cell carcinoma (SCC) who achieved a good response to induction chemotherapy followed by radiotherapy (1). In 2003 the Radiation Therapy Oncology Group (RTOG) trial 91-11 demonstrated the benefit of primary concurrent chemoradiotherapy in laryngeal preservation without a difference in survival $(2,3)$. Both

Correspondence to: Philippe Gorphe, Gustave Roussy, Department of Head and Neck Oncology, 114 rue Edouard Vaillant, F-94805 Villejuif, France. Tel: +33 142114586, Fax +33 142115194, email:Philippe.gorphe@gustaveroussy.fr

Key Words: Laryngeal neoplasm, fixed larynx, subglottic extension, laryngeal preservation, induction chemotherapy, radiotherapy, laryngectomy. studies led to a major paradigm shift from surgery to chemoradiotherapy for the treatment of advanced-stage pharyngo-laryngeal SCC $(4,5)$. However, the treatment must take into account laryngeal function preservation and quality of life $(6,7)$. In 2009, the Larynx Preservation Consensus Panel recommended using laryngo-esophageal dysfunctionfree survival (LEDFS) as a composite primary endpoint in preservation studies (8). To date, the results obtained using this end-point have never been published specifically for laryngeal cancer. We report on the outcomes of patients with resectable locally advanced American Joint Committee on Cancer (AJCC)/Union for International Cancer Control (UICC) T3 laryngeal SCC unamenable to partial laryngectomy with a large gross tumor size, a fixed hemilarynx or subglottic spread, treated with a laryngeal-preservation protocol.

\section{Patients and Methods}

Patients. This study received Institutional Review Board approval. We retrospectively reviewed patients treated at our cancer center between 2001 and 2013 for a laryngeal SCC. At our center, laryngeal-preservation protocols with induction chemotherapy for AJCC/UICC T3 tumors of the larynx is offered to patients with a resectable tumor unamenable to partial laryngectomy with a fixed hemilarynx or with compromised functions because of a large tumor volume or subglottic extension (SGE) not requiring a tracheotomy before treatment. Patients with small T3 tumors and a functional larynx were treated with concurrent chemoradiotherapy. Patients with a resectable T3 tumor and a non-functional larynx that required an initial tracheotomy or definitive enteral nutrition were treated with upfront total laryngectomy.

Treatments. Induction chemotherapy comprised three courses of a combination of cisplatin and fluorouracil $(\mathrm{PF})$, or more recently docetaxel, cisplatin and fluorouracil (TPF) administered every 3 weeks. Response was insufficient when tumor volume shrinkage was less than $50 \%$ clinically or radiologically, 2 weeks after the second cycle, or if the hemilarynx remained fixed. Radiotherapy was delivered at a dose of 70 Gy to good responders to induction chemotherapy. Patients with an insufficient response underwent a total laryngectomy with adjuvant radiotherapy according to 
Table I. Characteristics of 104 successive patients with American Joint Committee on Cancer/Union for International Cancer Control T3 intermediate gross laryngeal squamous-cell carcinoma treated with laryngeal preservation protocol with selection by induction chemotherapy.

$\begin{array}{lc}\text { Characteristic } & \\ \text { Gender, n (\%) } & \\ \quad \text { Male } & 93(89.4 \%) \\ \text { Female } & 11(10.6 \%) \\ & \\ \text { Median age (range), years } & 58(38-77) \\ \text { Initial disease site, n (\%) } & \\ \quad \text { Glottic } & 35(33.7 \%) \\ \quad \text { Supraglottic, epilaryngeal } & 53(51 \%) \\ \text { Supraglottic, other } & 16(15.3 \%) \\ \text { Laryngeal fixation, n (\%) } & \\ \text { Yes } & 42(40.4 \%) \\ \text { No } & 62(59.6 \%) \\ \text { Initial disease assessment, n (\%) } & \\ \text { Subglottic extension } & 23(22.1 \%) \\ \text { cN0 } & 55(52.9 \%) \\ \text { cN1 } & 16(15.3 \%) \\ \text { cN2a } & 8(7.7 \%) \\ \text { cN2b } & 6(5.8 \%) \\ \text { cN2c } & 10(9.6 \%) \\ \mathrm{cN} 3 & 9(8.7 \%)\end{array}$

pathological features and the patient's clinical status. When indicated, radiosensitizing agents (e.g. platinum-based chemotherapy or targeted therapy) were used.

Statistical design and analysis. Our main objective was to describe the results according to laryngeal fixation and SGE. Laryngeal fixation was defined as fixation of both the vocal cord and arytenoid cartilage (9). SGE was defined as tumor invasion $5 \mathrm{~mm}$ below the free margin of the vocal cords. Survival endpoints were defined as the time between the date of initial consultation in multidisciplinary staff for treatment proposal and the date of first event. The primary endpoint was LEDFS. The secondary endpoints were overall survival (OS), disease-free survival (DFS), laryngectomy-free survival (LFS) and laryngeal preservation.

The results are expressed as percentages or medians (with range), and data were analyzed using chi-squared tests. Analyses of LEDFS, OS and DFS were performed using the Kaplan-Meier method. The events for LEDFS were death, local relapse, total or partial laryngectomy, tracheotomy, and chronic enteral nutrition. The events for LFS were total laryngectomy or death. Death from any cause was the event for OS and the events for DFS were death or disease recurrence. Survival curves were compared using the logrank test for univariate analyses. Variables associated with a $p$-value of less than 0.1 in the univariate analyses and confounding variables correlated with initial laryngeal mobility were included in the multivariate analyses using a Cox model. Statistical analyses were performed using software Prism ${ }^{\circledR} 6.04$ (GraphPad Software, La Jolla, CA, USA) and STATA ${ }^{\circledR} 13.0$ software (StataCorp LP, College Station, TX, USA) for Windows. All reported $p$-values are twosided, and $p$-values lower than 0.05 were considered significant.
Table II. Details of evaluation outcomes and treatment given after induction chemotherapy in 104 sequential patients with American Joint Committee on Cancer/Union for International Cancer Control T3 intermediate gross laryngeal squamous-cell carcinoma. Good responders were treated with radiotherapy, insufficient responders were treated with total laryngectomy.

\begin{tabular}{llc}
\hline & \multicolumn{2}{c}{$\begin{array}{c}\text { No. of patients } \\
\text { Fixed larynx }\end{array}$} \\
\hline $\begin{array}{l}\text { Treatments and outcomes } \\
\text { Induction chemotherapy regimen }\end{array}$ & No & Yes \\
$\quad$ PF & 27 & 19 \\
TPF & 35 & 23 \\
Evaluation of volume response & 12 & 8 \\
$\quad$ Complete response & 34 & 21 \\
$\quad$ Partial response & 16 & 13 \\
$\quad$ Insufficient response & & 29 \\
Recovery of laryngeal mobility & 19 & 12 \\
Treatment after induction chemotherapy & 27 & 17 \\
$\quad$ Definitive radiotherapy & 1 & 4 \\
$\quad$ Concomitant chemoradiotherapy & 6 & 8 \\
Surgery alone & 9 & 1 \\
$\quad$ Surgery and radiotherapy & & \\
$\quad$ Surgery and chemoradiotherapy & & \\
\hline
\end{tabular}

PF: Cisplatin-fluorouracil; TPF: taxotere-cisplatin-fluorouracil.

\section{Results}

Patients. Between 2001 and 2013, 411 patients were treated at our Institution for a T3 SCC of the larynx. Study criteria requirements were fulfilled by 104 patients (Table I). Hemilaryngeal fixation was present in 42 patients and was more common in lesions originating from the glottis than from the supraglottis $(p=0.0194)$.

Induction chemotherapy and response. Fifteen patients (14.4\%) received only 2 cycles of chemotherapy: 10 achieved a complete response and were treated with radiotherapy, five failed to respond to induction chemotherapy and underwent a total laryngectomy. Details of tumor response and treatment received are given in Table II. The PF and TPF regimens were well balanced between groups. Disease in seven out of 29 patients operated on was upstaged from cT3 to pT4a $(24.1 \%)$ due to invasion through the thyroid cartilage in two cases and lysis of the cricoid cartilage, cricothyroid membrane invasion and prelaryngeal invasion in five.

Outcomes and survival. Recurrences occurred in nine patients submitted to a total laryngectomy (31\%), three of which were local (median time to onset, 3 months). After radiotherapy, eight patients (four with a fixed hemilarynx) required a definitive tracheotomy and eight patients (three 
Table III. Multivariate analyses of prognostic factors for laryngo-esophageal dysfuction-free survival (LEDFS), overall survival (OS), disease-free survival (DFS) and laryngectomy-free survival (LFS) in 104 patients treated with laryngeal-preservation protocol with induction chemotherapy for American Joint Committee on Cancer/Union for International Cancer Control T3 intermediate gross squamous-cell carcinoma of the larynx. Good responders were treated with radiotherapy, insufficient responders were treated with total laryngectomy.

\begin{tabular}{|c|c|c|c|c|c|c|c|c|}
\hline \multirow{3}{*}{ Variable } & \multicolumn{8}{|c|}{ Multivariate analyses } \\
\hline & \multicolumn{2}{|c|}{ LEDFS } & \multicolumn{2}{|c|}{ OS } & \multicolumn{2}{|c|}{ DFS } & \multicolumn{2}{|c|}{ LFS } \\
\hline & HR $(95 \% \mathrm{CI})$ & $p$-Value & HR $(95 \% \mathrm{CI})$ & $p$-Value & HR $(95 \% \mathrm{CI})$ & $p$-Value & HR $(95 \% \mathrm{CI})$ & $p$-Value \\
\hline Laryngeal fixation & $1.32(0.6-2.93)$ & 0.495 & $1.26(0.46-3.47)$ & 0.651 & $1.06(0.42-2.67)$ & 0.897 & $1.33(0.61-2.94)$ & 0.474 \\
\hline Glottic initial disease & $1.88(0.81-4.34)$ & 0.14 & $2.85(1.05-7.77)$ & 0.04 & $1.83(0.71-4.77)$ & 0.214 & $2.01(0.86-4.69)$ & 0.107 \\
\hline Subglottic extension & $0.54(0.21-1.41)$ & 0.209 & $0.14(0.04-0.51)$ & 0.003 & $0.3(0.1-0.89)$ & 0.03 & $0.52(0.2-1.36)$ & 0.183 \\
\hline Radiological nodal invasion & $1.27(0.68-2.38)$ & 0.448 & $1.67(0.79-3.53)$ & 0.181 & $1.27(0.65-2.47)$ & 0.48 & $1.19(0.63-2.22)$ & 0.594 \\
\hline PF chemotherapy & $1.28(0.78-2.11)$ & 0.327 & $1.25(0.69-2.28)$ & 0.462 & $1.04(0.6-1.82)$ & 0.881 & $1.22(0.73-2.03)$ & 0.449 \\
\hline Insufficient response & - & - & $1.39(0.68-2.82)$ & 0.364 & $1.02(0.5-2.08)$ & 0.96 & - & - \\
\hline
\end{tabular}

PF: Cisplatin-fluorouracil; HR:hazard ratio; CI: confidence interval.

with a fixed hemilarynx) required definitive enteral nutrition without a tracheotomy. One patient underwent a functional laryngectomy 22 months after the end of radiotherapy. Recurrences occurred in 24 patients treated with radiotherapy $(32 \%), 15$ of which were local $(20 \%$, eight with initial hemilaryngeal fixation). Fourteen patients underwent salvage total laryngectomy, in 11 cases performed within two years after the end of radiotherapy. In the total cohort, the 2- and 5-year laryngeal-preservation rates were $60.4 \%$ and $53.4 \%$, respectively, and the corresponding LFS rates were $46.1 \%$ and $30 \%$, respectively. The median LFS in the whole cohort was 21 months (Figure 1). SGE was associated with decreased LFS in the univariate analyses $(p=0.0215)$. The results of the multivariate analyses are reported in Table III.

Median LEDFS was 15 months (Figure 1). The 2- and 5year LEDFS rates were $44.3 \%$ and $28.2 \%$, respectively (Figure 1). LEDFS was not associated with initial hemilaryngeal fixation or SGE in the univariate analyses of the entire cohort ( $p=0.5772$ and $p=0.0623$, respectively), nor in the subgroup of patients treated with radiotherapy ( $p=0.9963$ and $p=0.6950$, respectively). The median OS and DFS for the whole cohort were 70 months and 44 months, respectively, (Figure 1). The 2- and 5-year OS rates were $70.4 \%$ and $54.5 \%$, respectively, and the corresponding DFS rates were $56 \%$ and $47.8 \%$, respectively. Decreased OS and DFS were associated with SGE in the univariate analyses ( $p=0.0109$ and $p=0.0456$, respectively) and multivariate analyses (Table III) but not with hemilaryngeal fixation ( $p=0.7490$ and $p=0.8841$, respectively). OS and DFS were not associated with a sufficient response or not (and therefore radiotherapy or surgery) ( $p=0.6546$ and $p=0.3006$, respectively) in the whole cohort, nor in patients with hemilarynx fixation $(p=0.846$ and $p=0.598)$ or with SGE $(p=0.529$ and $p=0.255$, respectively).

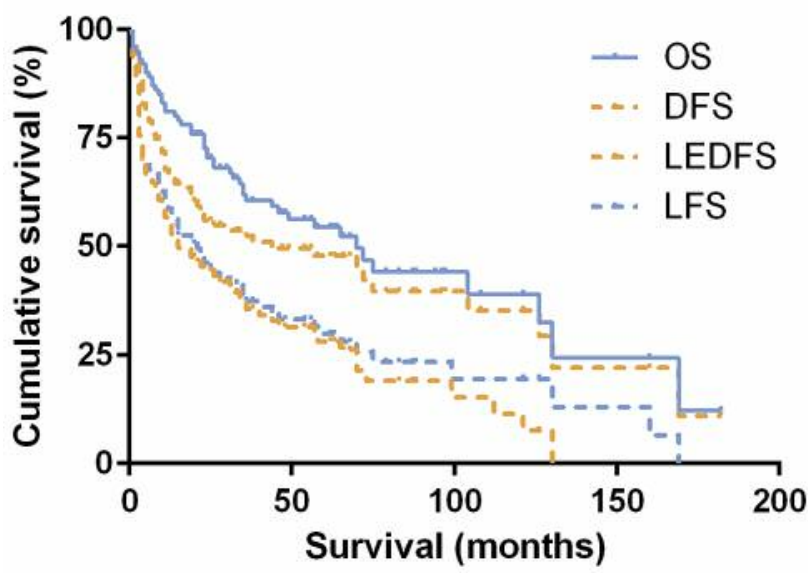

Figure 1. Kaplan-Meier curves of overall survival (OS), disease-free survival (DFS), laryngo-esophageal dysfunction-free survival (LEDFS) and laryngectomy-free survival (LFS) in 104 patients treated in laryngeal-preservation protocol with induction chemotherapy for American Joint Committee on Cancer/Union for International Cancer Control T3 intermediate gross squamous-cell carcinoma of the larynx.

\section{Discussion}

As expected, in our study, patients with T3 laryngeal cancer who achieved a good response to induction chemotherapy were able to benefit from treatment with radiotherapy without a decrease in survival compared to treatment with total laryngectomy with postoperative radiotherapy. Our major findings were the feasibility of chemoselection without compromised oncological or functional outcomes in patients with an initially fixed hemilarynx or SGE. The 2-year OS and 2-year laryngeal preservation rates in our cohort were 
Table IV. Available data of criteria of inclusion, evaluation and response with results of 2-year survival and laryngeal preservation in the four landmark randomized trials of laryngeal-preservation protocols with induction chemotherapy for selection of radiotherapy or total laryngectomy according to the response.

\begin{tabular}{|c|c|c|c|c|c|c|c|c|c|c|c|}
\hline \multirow[t]{2}{*}{ Trial (Ref) } & \multicolumn{4}{|c|}{ Inclusion criteria } & \multicolumn{3}{|c|}{ Evaluation criteria } & \multicolumn{2}{|c|}{ Response criteria } & \multirow[b]{2}{*}{$\begin{array}{c}\text { OS rate } \\
\text { (time } \\
\text { point) }\end{array}$} & \multirow[b]{2}{*}{$\begin{array}{c}\text { Laryngeal } \\
\text { preservation } \\
\text { rate } \\
\text { (time point) }\end{array}$} \\
\hline & Localization & Stage & T-Stage & $\begin{array}{c}\text { Laryngeal } \\
\text { mobility }\end{array}$ & $\begin{array}{l}\text { Inductior } \\
\text { CTx }\end{array}$ & $\begin{array}{c}\text { n Gross tumor } \\
\text { volume } \\
\text { evaluation }\end{array}$ & $\begin{array}{c}\text { Laryngeal } \\
\text { mobility }\end{array}$ & $\begin{array}{l}\text { Gross } \\
\text { tumor } \\
\text { response }\end{array}$ & $\begin{array}{c}\text { Laryngeal } \\
\text { mobility }\end{array}$ & & \\
\hline $\begin{array}{l}\text { VALCSG } \\
\text { (1) }\end{array}$ & Larynx & III, IV & $\begin{array}{c}\mathrm{T} 2, \mathrm{~T} 3, \\
\mathrm{~T} 4\end{array}$ & $\begin{array}{c}\text { Information: } \\
\text { Vocal cord } \\
\text { mobility } \\
\text { fixed or not }\end{array}$ & $\mathrm{PF}$ & $\begin{array}{c}\text { CT scan: } \\
\text { Radiological } \\
\text { product of } \\
\text { longest and } \\
\text { perpendicular } \\
\text { dimensions }\end{array}$ & NA & $\begin{array}{l}>50 \% \\
\text { Volume } \\
\text { response }\end{array}$ & NA & $\begin{array}{c}68 \% \\
(2-\text { year })\end{array}$ & NA \\
\hline $\begin{array}{l}\text { EORTC } \\
24891 \\
(10)\end{array}$ & Hypopharynx & $\begin{array}{l}\text { II, III, } \\
\text { IV } \\
\text { (except } \\
\text { N2c) }\end{array}$ & $\begin{array}{c}\mathrm{T} 2, \mathrm{~T} 3, \\
\mathrm{~T} 4\end{array}$ & NA & $\mathrm{PF}$ & $\begin{array}{c}\text { Clinical } \\
\text { macroscopic } \\
\text { evaluation by } \\
\text { direct endoscopy } \\
\text { performed } \\
\text { before } \\
\text { each cycle }\end{array}$ & NA & $\begin{array}{l}\text { Complete } \\
\text { response } \\
\text { after } 2 \text { nd } \\
\quad \text { or } \\
3 \text { rd cycle }\end{array}$ & $\begin{array}{l}\text { Complete } \\
\text { recovery }\end{array}$ & $\begin{array}{l}\text { Surgical } \\
\text { arm } \\
57 \% \text { vs. } \\
\text { radiotherapy } \\
\text { arm } 43 \% \\
\text { (3-year) }\end{array}$ & y \\
\hline $\begin{array}{l}\text { RTOG } \\
91-11 \\
(2)\end{array}$ & Larynx & III, IV & $\begin{array}{c}\mathrm{T} 2, \mathrm{~T} 3, \\
\text { low- } \\
\text { volume } \\
\mathrm{T} 4\end{array}$ & $\begin{array}{c}\text { Stratification: } \\
\text { vocal } \\
\text { cord } \\
\text { fixed } \\
\text { or not }\end{array}$ & : & $\begin{array}{c}\text { Clinical } \\
\text { macroscopic } \\
\text { evaluation } \\
\text { by direct } \\
\text { endoscopy } \\
\text { and CT scan } \\
\text { after } 2 \text { nd cycle }\end{array}$ & NA & $\begin{array}{l}\text { Complete or } \\
\text { partial } \\
\text { response }\end{array}$ & NA & $\begin{array}{c}76 \% \\
\text { (2-year) }\end{array}$ & $\begin{array}{c}75 \% \\
\text { (2-year) }\end{array}$ \\
\hline $\begin{array}{l}\text { GORTEC } \\
2000-01 \\
(11)\end{array}$ & $\begin{array}{c}\text { Larynx } \\
\text { and } \\
\text { hypopharynx }\end{array}$ & III, IV & $\begin{array}{l}\mathrm{T} 2, \mathrm{~T} 3, \\
\mathrm{~T} 4 \\
\text { without } \\
\text { massive } \\
\text { cartilage } \\
\text { invasion }\end{array}$ & $\begin{array}{l}\text { Information: } \\
\text { Vocal cord } \\
\text { mobility } \\
\text { normal, } \\
\text { impaired } \\
\text { of fixed }\end{array}$ & $\begin{array}{l}\text { PF } \\
v s . \\
\text { TPF }\end{array}$ & $\begin{array}{c}\text { Clinical } \\
\text { examination } \\
\text { (indirect } \\
\text { laryngoscopy) } \\
\text { and CT scan }\end{array}$ & $\begin{array}{c}\text { Clinical } \\
\text { examination } \\
\text { (indirect } \\
\text { laryngoscopy) }\end{array}$ & $\begin{array}{l}\text { Complete } \\
\text { response } \\
\text { at primary } \\
\text { site or } \\
\text { partial } \\
\text { response } \\
>80 \% \\
\text { and normal } \\
\text { laryngeal } \\
\text { mobility }\end{array}$ & Normal & $\begin{array}{c}60 \% \\
(3-y e a r)\end{array}$ & $\begin{array}{c}57.5 \% \text { vs. } \\
70.3 \% \\
\text { (3-year) }\end{array}$ \\
\hline
\end{tabular}

VALCSG: Veterans Affairs Laryngeal Cancer Study Group; CTx: chemotherapy; CT: computed tomography; OS: overall survival; RTOG: Radiation Therapy Oncology Group; EORTC: European Organization for Research and Treatment of Cancer; GORTEC: Groupe Oncologie Radiothérapie Tête Et Cou; NA: Not available; PF: cisplatin-fluorouracil; TPF: taxotere-cisplatin-fluorouracil.

$70.4 \%$ and $60.4 \%$, respectively, similar to the results of the landmark laryngeal preservation trials (Table IV) (1-3, 1013). The 2-year LEDFS rate in our series was $44.3 \%$ and can be used as a benchmark. However, it is difficult to compare articles on laryngeal preservation due to the heterogeneity of inclusion and evaluation criteria (Table IV).

It may seem logical to study laryngeal and hypopharyngeal neoplasms at the same time due to the same issue of deciding between radical surgery and laryngeal preservation. However, the survival results of patients with laryngeal and hypopharyngeal neoplasms and the functional sequelae of treatment are widely different. In fact the AJCC/UICC TNM staging of the larynx takes into account vocal cord mobility which is staged normal, impaired or fixed whereas staging of the hypopharynx takes into account hemilaryngeal fixation which is defined as fixation of both the vocal cord and arytenoid and is staged as fixed or not. In our experience, impaired laryngeal function is associated with hemilaryngeal fixation more than with vocal cord fixation itself, which can be consistent with normal or subnormal function (14). The heterogeneity of mobility criteria in scientific articles prohibits a comparison of results according to the initial functional assessment.

Moreover the landmark trials included patients with AJCC/UICC stages III/IV with very diverse gross tumors, local 
extension and nodal involvement $(1,2,10,11)$. In patients with $\mathrm{T} 2$ lesions, the larynx almost always remains functional as in the case of most patients with T3 lesions because of local extension such as minimal invasion of the pre-epiglottic space or paraglottic space. These patients, whose tumors represented $24.1 \%$ of the T3 lesions in our study period, were treated with concurrent chemoradiotherapy because in our opinion, the response rate after induction chemotherapy is very high for these low-volume tumors and the laryngeal mobility cannot be used as decision criterion due to the absence of laryngeal fixation. In contrast, treatment with upfront chemoradiotherapy has been reported for T4 tumors but is still controversial because of selection biases and continues to fuel debate because of a low level of evidence $(6,15-21)$. The standards upheld at our Institution remain in accordance with the National Comprehensive Cancer Network Guidelines which recommend upfront total laryngectomy with postoperative radiotherapy in patients with $\mathrm{T} 4 \mathrm{a}$ tumors by seventh edition AJCC criteria (22). Patients who refuse surgery are given concurrent chemoradiotherapy because radiotherapy would ultimately be selected whatever the response to induction chemotherapy.

Our study allowed us to confirm that SGE is an important prognostic factor in laryngeal cancer regardless of treatment. SGE is usually considered to confer a poor prognosis given the high propensity for nodal and distant spread, and the risk of an obstructive lesion with impaired laryngeal function. We previously reported the feasibility of laryngeal preservation in cancer with SGE, with a strategy fine-tuned to the disease stage and local extension (23). We confirm in this study the feasibility of laryngeal preservation in patients with locally advanced T3 intermediate gross laryngeal tumors with SGE or a fixed hemilarynx without compromised outcomes as long as the selection criteria after induction chemotherapy remain rigorously respected.

\section{Conflicts of Interest}

None.

\section{Acknowledgements}

The Authors thank Lorna Saint Ange for editing.

\section{References}

1 Induction chemotherapy plus radiation compared with surgery plus radiation in patients with advanced laryngeal cancer. The Department of Veterans Affairs Laryngeal Cancer Study Group. N Engl J Med 324(24): 1685-1690, 1991.

2 Forastiere AA, Goepfert H, Maor M, Pajak TF, Weber R, Morrison W, Glisson B, Trotti A, Ridge JA, Chao C, Peters G, Lee DJ, Leaf A, Ensley J and Cooper J: Concurrent chemotherapy and radiotherapy for organ preservation in advanced laryngeal cancer. N Engl J Med 349(22): 2091-2098, 2003.
3 Forastiere AA, Zhang Q, Weber RS, Maor MH, Goepfert H, Pajak TF, Morrison W, Glisson B, Trotti A, Ridge JA, Thorstad W, Wagner H, Ensley JF and Cooper JS: Long-term results of RTOG 91-11: A comparison of three nonsurgical treatment strategies to preserve the larynx in patients with locally advanced larynx cancer. J Clin Oncol 31(7): 845-852, 2013.

4 Maddox PT and Davies L: Trends in total laryngectomy in the era of organ preservation: A population-based study. Otolaryngol Head Neck Surg 147(1): 85-90, 2012.

5 Chen AY, Fedewa S and Zhu J: Temporal trends in the treatment of early- and advanced-stage laryngeal cancer in the United States, 1985-2007. Arch Otolaryngol Head Neck Surg 137(10): 1017-1024, 2011.

6 Forastiere AA, Weber RS and Trotti A: Organ preservation for advanced larynx cancer: Issues and outcomes. J Clin Oncol 33(29): 3262-3268, 2015.

7 Hamilton DW, Bins JE, McMeekin P, Pedersen A, Steen N, De Soyza A, Thomson R, Paleri V and Wilson JA: Quality compared to quantity of life in laryngeal cancer: A time tradeoff study. Head Neck 38(Suppl 1): E631-637, 2016.

8 Lefebvre JL, Ang KK and Larynx Preservation Consensus P: Larynx preservation clinical trial design: Key issues and recommendations-a consensus panel summary. Int $\mathrm{J}$ Radiat Oncol Biol Phys 73(5): 1293-1303, 2009.

9 Brasnu D, Laccourreye H, Dulmet E and Jaubert F: Mobility of the vocal cord and the arytenoid in cancer of the larynx and the hypopharynx. Anatomo-clinical study. Ann Otolaryngol Chir Cervicofac 105(6): 435-441, 1988

10 Lefebvre JL, Chevalier D, Luboinski B, Kirkpatrick A, Collette $\mathrm{L}$ and Sahmoud T: Larynx preservation in pyriform sinus cancer: Preliminary results of a european organization for research and treatment of cancer phase III trial. EORTC Head and Neck Cancer Cooperative Group. J Natl Cancer Inst 88(13): 890-899, 1996.

11 Pointreau Y, Garaud P, Chapet S, Sire C, Tuchais C, Tortochaux J, Faivre S, Guerrif S, Alfonsi M and Calais G: Randomized trial of induction chemotherapy with cisplatin and 5-fluorouracil with or without docetaxel for larynx preservation. J Natl Cancer Inst 101(7): 498-506, 2009.

12 Lefebvre JL, Andry G, Chevalier D, Luboinski B, Collette L, Traissac L, de Raucourt D, Langendijk JA, Head E and Neck Cancer G: Laryngeal preservation with induction chemotherapy for hypopharyngeal squamous cell carcinoma: 10-year results of EORTC trial 24891. Ann Oncol 23(10): 2708-2714, 2012.

13 Janoray G, Pointreau Y, Garaud P, Chapet S, Alfonsi M, Sire C, Jadaud E and Calais G: Long-term results of a multicenter randomized phase III trial of induction chemotherapy with cisplatin, 5-fluorouracil, +/- docetaxel for larynx preservation. $\mathbf{J}$ Natl Cancer Inst 108(4): djv368, 2016. doi: 10.1093/jnci/djv368

14 Janot F, Rhein B, Koka VN, Wibault P, Domenge C, Bessede JP, Marandas P, Schwaab G and Luboinski B: Laryngeal preservation with induction chemotherapy. Experience of two GETTEC centers, between 1985 and 1995. Ann Otolaryngol Chir Cervicofac 119(1): 12-20, 2002.

15 Rosenthal DI, Mohamed AS, Weber RS, Garden AS, Sevak PR, Kies MS, Morrison WH, Lewin JS, El-Naggar AK, Ginsberg LE, Kocak-Uzel E, Ang KK and Fuller CD: Long-term outcomes after surgical or nonsurgical initial therapy for patients with T4 squamous cell carcinoma of the larynx: A 3-decade survey. Cancer 121(10): 1608-1619, 2015. 
16 Issa MR, Samuels SE, Bellile E, Shalabi FL, Eisbruch A and Wolf G: Tumor volumes and prognosis in laryngeal cancer. Cancers 7(4): 2236-2261, 2015

17 Rutkowski T: The role of tumor volume in radiotherapy of patients with head and neck cancer. Radiat Oncol 9: 23, 2014.

18 Strojan P, Haigentz M, Jr., Bradford CR, Wolf GT, Hartl DM, Langendijk JA, Rinaldo A, Eisbruch A, Mendenhall WM, Forastiere AA, Takes RP and Ferlito A: Chemoradiotherapy vs. total laryngectomy for primary treatment of advanced laryngeal squamous cell carcinoma. Oral Oncol 49(4): 283-286, 2013.

19 Stenson KM, Maccracken E, Kunnavakkam R, EE WC, Portugal LD, Villaflor V, Seiwert T, Blair E, Haraf DJ, Salama JK and Vokes EE: Chemoradiation for patients with large-volume laryngeal cancers. Head Neck 34(8): 1162-1167, 2012.

20 Knab BR, Salama JK, Solanki A, Stenson KM, Cohen EE, Witt ME, Haraf DJ and Vokes EE: Functional organ preservation with definitive chemoradiotherapy for $\mathrm{t} 4$ laryngeal squamous cell carcinoma. Ann Oncol 19(9): 1650-1654, 2008.
21 Weber RS, Forastiere A, Rosenthal DI and Laccourreye O: Controversies in the management of advanced laryngeal squamous cell carcinoma. Cancer 101(2): 211-219, 2004.

22 Gorphe P, Matias M, Moya-Plana A, Tabarino F, Blanchard P, Tao Y, Janot F and Temam S: Results and survival of locally advanced AJCC 7th edition T4A laryngeal squamous cell carcinoma treated with primary total laryngectomy and postoperative radiotherapy. Ann Surg Oncol, 2016.

23 Levy A, Blanchard P, Temam S, Maison MM, Janot F, Mirghani H, Bidault F, Guigay J, Lusinchi A, Bourhis J, Daly-Schveitzer $\mathrm{N}$ and Tao Y: Squamous cell carcinoma of the larynx with subglottic extension: Is larynx preservation possible? Strahlenther Onkol 190(7): 654-660, 2014.

Received September 22, 2016

Revised October 5, 2016

Accepted October 12, 2016 